\title{
Outcomes associated with initiation of tiotropium or fluticasone/salmeterol in patients with chronic obstructive pulmonary disease
}

This article was published in the following Dove Press journal:

Patient Preference and Adherence

22 July 20II

Number of times this article has been viewed

\author{
Rachel Halpern' \\ Christine L Baker ${ }^{2}$ \\ Jun $\mathrm{Su}^{3}$ \\ Kimberly B Woodruff ${ }^{2}$ \\ Ryne Paulose-Ram² \\ Victoria Porter' \\ Hemal Shah ${ }^{4}$ \\ 'Health Economics and Outcomes \\ Research, Optumlnsight, Eden Prairie, \\ MN, USA; ${ }^{2}$ Global Market Access, \\ Primary Care Business Unit, Pfizer \\ Inc, New York, NY, USA; ${ }^{3}$ Health \\ Economics and Outcomes Research, \\ Boehringer-Ingelheim Pharmaceuticals \\ Inc, Ridgefield, CT, USA; ${ }^{4}$ Former \\ employee of Boehringer Ingelheim \\ Pharmaceuticals Inc, Ridgefield, CT, USA
}

Correspondence: Rachel Halpern Optumlnsight, I 2 I 25 Technology Drive, Eden Prairie, MN 55344, USA

Tel + I 9528336280

Fax +l 9528336045

Email rachel.halpern@innovus.com
Introduction: Adherence to long-acting bronchodilator therapy for management of chronic obstructive pulmonary disease (COPD) is a critical clinical and cost issue. Low adherence is associated with relatively higher exacerbation rates and illness burden.

Purpose: To compare adherence between patients with COPD initiating therapy on tiotropium or fluticasone/salmeterol and examine the association between adherence and respiratory-related costs.

Patients and methods: This retrospective claims data analysis evaluated patients initiating tiotropium or combination fluticasone/salmeterol from December 1, 2004 to December 31, 2005. Patients had $\geq 1$ COPD diagnosis (International Classification of Diseases, 9th Revision, Clinical Modification [ICD-9-CM] 491.xx, 492.x, 496) and were observed during 6-month pre-index and variable (12-18-month) post-index periods. Outcomes were adherence to and discontinuation of therapy, and respiratory-related inpatient, medical, and total health care costs. Adherence was medication possession ratio $\geq 0.80$. Discontinuation, adherence, and costs were analyzed with Cox proportional hazards regression, logistic regression, and generalized linear model regressions, respectively. Regressions controlled for demographic, sociodemographic, and health status factors.

Results: The study population comprised 1561 tiotropium and 2976 fluticasone/salmeterol patients. In unadjusted comparisons: $19.5 \%$ and $8.5 \%$ of tiotropium and fluticasone/salmeterol patients, respectively, were adherent $(P<0.001)$; tiotropium patients versus fluticasone/salmeterol patients had higher mean respiratory-related pharmacy costs (US\$1080 versus US\$974, $P=0.002)$ and health care costs (US\$3751 versus US\$2932, $P=0.031)$. Regression analysis showed tiotropium patients were $31.6 \%$ less likely to discontinue therapy ( $95 \%$ confidence interval [CI]: 0.64-0.73) and had 2.25 times higher odds of adherence (CI: 1.85-2.73) versus fluticasone/ salmeterol patients. The associations between index therapy and costs were not significant. Adherence versus nonadherence was associated with: 46.9\% higher health care costs (CI: 1.13-1.91); $37.1 \%$ lower medical costs (CI: $0.43-0.91$ ); and 53.4\% lower inpatient costs (CI: $0.30-0.72$ ).

Conclusion: Patients with COPD initiating long-acting bronchodilator therapy were more likely to be adherent to tiotropium than to fluticasone/salmeterol. Adherence to either tiotropium or to fluticasone/salmeterol was associated with lower respiratory-related medical and inpatient costs, and with higher respiratory-related total health care costs.

Keywords: bronchodilator agents, health care costs, medication adherence, COPD, retrospective studies

\section{Introduction}

Chronic obstructive pulmonary disease (COPD) is a disorder characterized by airflow limitation that is "not fully reversible" and progressive lung function decline. ${ }^{1,2}$ Chronic 
bronchitis and emphysema are the two main components of COPD. ${ }^{1,2}$ COPD is the fourth leading cause of death in the United States, ${ }^{1}$ and it is estimated that it will be the third leading cause of death by $2020 .^{3}$ Approximately 12 million US adults are diagnosed with COPD, and another 12 million may have the disease but remain undiagnosed. ${ }^{4}$ The burden of COPD on the United States health care system is considerable. Estimates from research conducted in 2000 showed that COPD was associated with approximately 1.5 million emergency department visits, 726,000 hospitalizations, and 119,000 deaths per year. ${ }^{5}$ A more recent estimate linked COPD with US\$42.6 billion in US health care costs and lost productivity in $2007 .{ }^{6}$

Current approaches to managing COPD are aimed at treating both the symptoms and the underlying pulmonary inflammation and bronchoconstriction associated with the disorder. Pharmacologic therapy for COPD includes shortacting and long-acting beta-agonists (SABAs, LABAs), anticholinergic agents, methylxanthines, and inhaled glucocorticosteroids. ${ }^{1,2,7}$ The 2009 update to the Global Initiative for Chronic Obstructive Lung Disease (GOLD) guidelines, ${ }^{2}$ as well as other national guidelines, ${ }^{8}$ recommend treatment with long-acting bronchodilators, including oncedaily anticholinergic tiotropium, for management of stable Stage II moderate COPD. The GOLD guidelines specify that treatment with inhaled glucocorticosteroids, alone or in combination with inhaled beta-agonists, may be indicated for the management of more severe COPD. ${ }^{2}$

Nevertheless, despite the widespread availability of practice guidelines for outpatient management of COPD, research indicates that these guidelines are underutilized in "real-world" clinical practice. ${ }^{9,10}$ A survey of 784 primary care physicians who actively treated COPD patients revealed that only $55 \%$ were cognizant of COPD treatment guidelines and $25 \%$ factored guidelines into their treatment decisions. Additionally, $32 \%$ of the primary care physicians treated patients with mild COPD with inhaled corticosteroids. ${ }^{9}$

Furthermore, several studies have shown that even when these guidelines are followed, adherence to recommended therapy is poor among COPD patients, ${ }^{11}$ as is often the case with individuals requiring long-term therapy for chronic diseases. ${ }^{12,13}$ The underuse of COPD medications has been reported in numerous studies, both in clinical trial settings and in "real-world" clinical practice settings. ${ }^{14-19}$ Results of the Lung Health Study, a double-blind, multicenter, randomized controlled trial of smoking intervention and bronchodilator use in COPD patients, showed a decline in self-reported adherence from $70 \%$ of patients at 4 -month follow up to $60 \%$ over the next 18 months. ${ }^{20}$ Overall, the results of studies conducted in a variety of settings indicate that average adherence to COPD regimens is $50 \%$ or lower. ${ }^{13,14,16-18,21}$ The literature indicates that: (1) physicians who treat patients with COPD do not uniformly adhere to treatment guidelines; and (2) patients frequently are not adherent to bronchodilator therapy.

Adherence to COPD treatments, particularly to longacting bronchodilators, is a critical clinical and health economics issue affecting the management of stable COPD because of its well documented impact on a wide variety of health outcomes. ${ }^{12,16,22}$ Greater adherence to COPD medications has been shown to be associated with lower rates of exacerbations, fewer emergency room visits and inpatient hospitalizations, shorter lengths of inpatient stays, less inefficient escalation of therapy, lower health care expenditures, and higher quality of life. ${ }^{15,16,22-27}$

Most of the published literature documenting adherence to COPD therapies examines medications that have been on the market for several years (eg, short-acting anticholinergics, inhaled corticosteroids, LABAs) or results from clinical trials. There is little information on adherence to newer long-acting bronchodilators.

\section{Study objectives}

The objectives of this retrospective claims study were to: (1) compare adherence between COPD patients initiating long-acting bronchodilator therapy on tiotropium or fluticasone/salmeterol; and (2) examine the association between adherence to these therapies and respiratory-related costs. We hypothesized that: (1) adherence levels would differ between patients treated with tiotropium and those treated with fluticasone/salmeterol; and (2) better adherence to longacting bronchodilator therapy would be associated with lower respiratory-related medical costs. To our knowledge, there are no studies in the published literature that compare adherence to these two long-acting bronchodilator therapies.

\section{Materials and methods Data source}

The retrospective administrative claims data used in this study included medical claims, pharmacy claims, and eligibility information from a large, national US health plan. The plan provides fully insured coverage for professional (eg, physician), facility (eg, hospital), and outpatient prescription medication services. Professional and facility claims include International Classification of Diseases, 9th Revision, Clinical Modification (ICD-9-CM) diagnosis codes, ICD-9 
procedure codes, Current Procedural Terminology, Version 4 (CPT-4) procedure codes, Healthcare Common Procedure Coding System (HCPCS) procedure codes, site of service codes, provider specialty codes, and health plan and patient costs. Outpatient pharmacy claims provide National Drug Codes (NDC) for dispensed medications, quantity dispensed, drug strength, days supply, provider specialty code, and health plan and patient costs.

The individuals covered by this health plan, about 14 million in 2007, are geographically diverse across the United States, with greatest representation in the South and Midwest US census regions. Prior to the commencement of this study, claims data were linked at the individual level with an external database that contains measures of sociodemographic characteristics, including race and ethnicity, and household income; after this linkage, all patient identification information (eg, date of birth) was removed and replaced with the unique anonymous patient identification numbers associated with individual health plan enrollees in the claims. The sociodemographic data measures were generated by a combination of self-report, modeling, census data, and a variety of other individual-level and population-level data sources. Although identifying information was not required to link the sociodemographic data with the claims data, we obtained approval from a privacy board to ensure that use of the sociodemographic data would not risk individual patient identification. All study data were made unidentifiable and accessed with protocols compliant with the Health Insurance Portability and Accountability Act enacted by the US Congress in 1996.

\section{Subject identification}

The study population comprised commercial health plan members diagnosed with COPD and initiated on tiotropium or fluticasone/salmeterol. (This study was originally designed to include patients initiated on long-acting bronchodilators, including salmeterol and formoterol, as well as on tiotropium or fluticasone/salmeterol. Ultimately, the numbers of patients initiated on salmeterol $(\mathrm{N}=128)$ or formoterol $(\mathrm{N}=111)$ after application of the selection criteria were very small. Consequently, only tiotropium ( $\mathrm{N}=1561)$ and fluticasone/ salmeterol $(\mathrm{N}=2976)$ cohorts were retained and analyzed.) All patients had at least one pharmacy claim for one of these two medications during the identification period December 1 , 2004 through December 31, 2005. The date of the first tiotropium or fluticasone/salmeterol pharmacy claim was defined as the "index date", and the medication on the index prescription claim was defined as the "index therapy". All patients were at least 40 years old during the year of the index date, and had 6 months of pre-index date ("baseline") and at least 12 months, up to 18 months, of post-index date ("follow up") continuous enrollment with medical and pharmacy benefits. In addition, patients were required to have at least one medical claim with a primary or secondary ICD-9-CM diagnosis code for COPD (ICD-9-CM 491.xx, 492.x, 496) during the baseline period or within 60 days after the index date. Patients with any pharmacy claims for tiotropium, fluticasone/salmeterol, salmeterol, or formoterol during the baseline period were excluded from the study population in order to focus on those initiating long-acting therapy. Patients with medical claims with primary or secondary ICD-9-CM codes for asthma (ICD-9-CM 493.xx), cystic fibrosis (ICD-9-CM 277.0x), or lung cancer (ICD-9-CM 162.2-162.9, 197.0, $212.3,231.2,235.7,239.1)$ at any time during the baseline or follow up periods also were excluded.

\section{Cohort assignment}

Patients were divided into tiotropium and fluticasone/salmeterol cohorts. Patients were assigned to the tiotropium cohort if their index therapy was tiotropium; if they also had a pharmacy claim for fluticasone/salmeterol within 2 weeks after the index date, they remained in the tiotropium cohort if they had at least two pharmacy claims for tiotropium and only one claim for fluticasone/salmeterol throughout follow up (including index date). Conversely, patients were assigned to the fluticasone/salmeterol cohort if their index therapy was fluticasone/salmeterol; if they had a claim for tiotropium within the 2 weeks after the index date, they remained in the cohort if they had at least two fluticasone/salmeterol claims and only one tiotropium claim throughout follow up. Patients who had pharmacy claims each for tiotropium and fluticasone/salmeterol within 2 weeks after the index date and at least two claims each for fluticasone/salmeterol and tiotropium throughout follow up (ie, patients who might have been concurrently treated with tiotropium and fluticasone/ salmeterol) were excluded in order to limit the study population to patients initiated on only one of the therapies.

\section{Variables \\ Outcomes}

Adherence and therapy discontinuation with the index therapy were assessed during the follow up period inclusive of the index date. Adherence was measured with a continuous medication possession ratio (MPR): (cumulative days supply of the index therapy during follow up)/ (number of days of follow up). The number of days spent in 
inpatient facilities was subtracted from both the numerator and denominator of the MPR based on the assumption that COPD therapy was administered during any inpatient stay. ${ }^{28}$ MPR values greater than 1.0 were truncated to 1.0 . The continuous MPR value (between 0.0 and 1.0) was also converted to a binary indicator such that MPR $\geq 0.80$ was "adherent" 29 and MPR $<0.80$ was "nonadherent". Therapy discontinuation was defined as a lapse, or "gap", in therapy, and occurred when more than 30 days elapsed between the "run-out" date (ie, the date of the last fill plus its days supply) of an index therapy fill and the next refill or the end of the follow up period. Discontinuation was also defined with a 60 day gap threshold. Both measures of discontinuation were adjusted for early refills.

Respiratory-related cost outcome measures included medical costs, outpatient pharmacy costs, total health care (medical + outpatient pharmacy) costs, and inpatient costs associated with a broad variety of respiratory conditions. Inpatient costs were a subset of the respiratory-related medical costs. Respiratory-related medical care was identified from medical claims with primary diagnoses for respiratory conditions or respiratory failure; or diagnoses associated with respiratory conditions or respiratory failure secondary to primary diagnoses for cardiac conditions. The ICD-9-CM diagnosis codes used to identify respiratory conditions or respiratory failure and cardiac conditions are shown in Appendix A and Appendix B, respectively. Respiratoryrelated pharmacy costs represented costs for medications associated with the designated respiratory conditions, and were based on pharmacy claims for tiotropium, fluticasone/ salmeterol, LABAs (salmeterol, formoterol), SABAs (isoproterenol, isoetharine, metaproterenol, terbutaline, albuterol, bitolterol, pirbuterol, levalbuterol), short-acting anticholinergics (ipratropium), theophylline, inhaled corticosteroids (beclomethasone, flunisolide, dexamethasone, triamcinolone, mometasone, budesonide, fluticasone), and oral prednisone. Costs were the sum of health plan-paid and patient-paid amounts (ie, not charged amounts) and were adjusted for inflation up to 2006 using the medical care cost component of the Consumer Price Index.

Cost variables were not standardized to a uniform period (eg, per patient per month or annualized) because length of follow up was uniform within the study population. The mean (standard deviation [SD]) lengths of follow up for the tiotropium and fluticasone/salmeterol cohorts were 502.7 (58.5) days and 508.0 (57.1) days, respectively; these lengths of follow up, although significantly different $(P=0.004$, data not shown), were nevertheless quite close. The median length of follow up for both cohorts was 547 days, which also was the maximum length of follow up. The lengths of follow up at the 25 th percentile for the tiotropium and fluticasone/salmeterol cohorts were 459.0 and 470.5 days, respectively.

\section{Demographic, sociodemographic, and clinical characteristics}

Demographic variables (age, gender, and geographic region) were captured from the enrollment data. Race was measured as a binary indicator, white/nonwhite, where "white" denotes non-Hispanic Caucasian. Household income was measured as a categorical variable. Clinical characteristics were measured during the baseline period and included: indication of respiratory complication; comorbid conditions (hypertension, heart disease, lipid metabolism, respiratory infection); Charlson Comorbidity Index (CCI) score; and use of SABAs or short-acting anticholinergics, corticosteroids, and oxygen services. Baseline respiratory complication was a binary flag to identify patients who had at least one baseline respiratory-related inpatient stay or emergency department visit. This measure was modeled on a similar measure of acute COPD exacerbation, also based on respiratory-related hospitalization or emergency department visit, used by Chrischilles et al; ${ }^{30}$ their definition of "respiratory-related" included diagnoses of COPD, asthma, emphysema, chronic or acute bronchitis, and pneumonia. We generalized the measure of respiratory complication to include the broader diagnostic criteria for "respiratory-related" used in this study. The comorbidities of hypertension, heart disease, disorders of lipid metabolism, and respiratory infection were identified with the Clinical Classification Software managed by the Agency for Healthcare Research and Quality. ${ }^{31}$ CCI was based on the Quan et al ${ }^{32}$ update of the Deyo et $\mathrm{al}^{33}$ adaptation of the original Charlson et al index. ${ }^{34}$ SABA use was a binary indicator to identify patients with at least one SABA or short-acting anticholinergic pharmacy claim. Corticosteroid use was a binary indicator based on inhaled corticosteroid or oral prednisone pharmacy claims. Use of oxygen services was identified with medical claims containing HCPCS codes A4611-A4629, E0424-E0486, E0550-E0585, E1353-E1406, or S8120-S8121. In addition, a binary indicator showed whether the index therapy fill (on index date) was associated with a pulmonology specialty code as a proxy for intensity of services consumption.

\section{Statistical analysis}

All study variables were analyzed descriptively. Results were stratified by cohort; respiratory-related costs also were 
stratified by adherence within cohort. $T$-tests were used to examine differences between unadjusted mean values of continuous variables, accounting for unequal variance as appropriate, and chi-square tests were used to evaluate unadjusted differences in proportions.

Regression analysis was employed to analyze factors associated with discontinuation, adherence, and respiratoryrelated health care costs, medical costs, and inpatient costs, while controlling for covariates. Time to first discontinuation (both 30 day and 60 day gap criteria) was modeled using Cox proportional hazards regression. Adherence was modeled with logistic regression. Generalized linear model (GLM) regressions with log link and gamma distribution were estimated to evaluate respiratory-related costs. Respiratory-related medical costs and inpatient costs were analyzed with two-part cost models: the first part was a logistic regression to model whether the patient had any respiratory-related medical or inpatient costs ( $>$ US $\$ 0$ ); the second part was GLM to model actual costs among those who had cost $>$ US $\$ 0$. The gamma distribution used in all GLM regressions was selected based on the Park test. ${ }^{35}$ A two-part cost model was not necessary to model respiratory-related health care costs because all patients had cost $>$ US\$0. Independent variables included: index therapy cohort; age category; gender; pulmonologist-prescribed index therapy fill; baseline respiratory complication; CCI score; baseline SABA, corticosteroid, and oxygen utilization; and baseline comorbid conditions. The binary adherence indicator was also an independent variable in the cost models.

Sensitivity testing was conducted for the adherence and cost regressions. An alternative threshold of MPR $\geq 0.70$ was employed for the logistic regression to model adherence. Additional cost regressions that added geographic region indicators as covariates and that excluded the adherence (MPR $\geq 0.80$ ) indicator were estimated. All analysis was performed with SAS, Version 9, and Stata, Version 9.

\section{Results \\ Descriptive analysis results}

The study population numbered 4537 patients, of whom 1561 initiated tiotropium therapy and 2976 initiated fluticasone/salmeterol therapy; patient selection and attrition are shown in Figure 1. Demographic and sociodemographic characteristics of the study population, by cohort, are shown in Table 1. The mean (SD) ages within cohorts were 62.0 (10.4) years in the tiotropium cohort and 60.3 (10.7) years in the fluticasone/salmeterol cohort (data not shown, $P<0.001$ ). Consistent with the national coverage of the
Individuals $\geq 40$ years old with $\geq 1$ claim for longacting bronchodilator during identification period $12 / 1 / 04-12 / 31 / 05$

$\mathrm{N}=257,815$

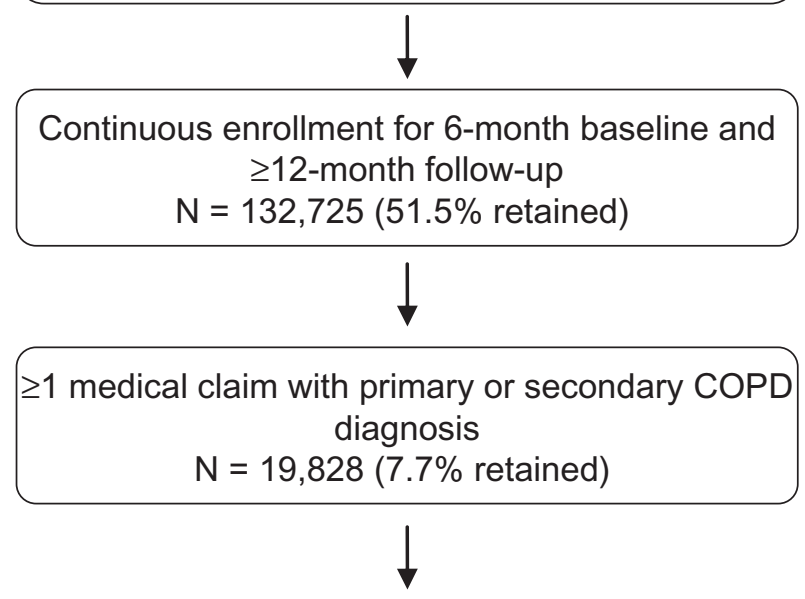

No medical claims with asthma, cystic fibrosis, or lung cancer diagnoses

$N=8,260(3.2 \%$ retained $)$

Individuals who can be assigned to tiotropium and fluticasone/salmeterol cohorts (ie, not salmeterol or formoterol, not concurrent tiotropium + fluticasone/salmeterol therapy at index date) $\mathrm{N}=6,977(2.7 \%$ retained $)$

Initiating long-acting bronchodilator therapy on index date $\mathrm{N}=4,537(1.8 \%$ retained $)$

Figure I Study population selection and attrition.

health plan, about three-quarters of each cohort was enrolled in the South or Midwest regions. Approximately $60 \%$ of patients in each cohort had household income levels lower than US\$70,000. There was a small but significant difference in the proportion of white patients by cohort: $85.8 \%$ in the tiotropium cohort compared with $83.5 \%$ in the fluticasone/ salmeterol cohort $(P=0.037)$.

Baseline clinical characteristics are presented in Table 2. There were few significant differences between the tiotropium and fluticasone/salmeterol cohorts. Higher proportions of the tiotropium cohort had SABA use and oxygen use during baseline: $36.9 \%$ of the tiotropium cohort had at least 
Table I Demographic and sociodemographic characteristics by index therapy cohort

\begin{tabular}{|c|c|c|c|c|c|}
\hline & \multicolumn{2}{|c|}{$\begin{array}{l}\text { Tiotropium } \\
(N=1561)\end{array}$} & \multicolumn{2}{|c|}{$\begin{array}{l}\text { Fluticasone/ } \\
\text { salmeterol } \\
(\mathbf{N}=\mathbf{2 9 7 6})\end{array}$} & \multirow[t]{2}{*}{$P$-value } \\
\hline & $\mathbf{N}$ & $\%$ & $\mathbf{N}$ & $\%$ & \\
\hline \multicolumn{6}{|l|}{ Age category } \\
\hline $40-54$ & 367 & 23.5 & 935 & 31.4 & $<0.001$ \\
\hline $55-64$ & 673 & 43.1 & $|| 6 \mid$, & 39.0 & 0.007 \\
\hline $65-74$ & 301 & 19.3 & 509 & 17.1 & 0.069 \\
\hline $75+$ & 220 & 14.1 & 371 & 12.5 & 0.122 \\
\hline \multicolumn{6}{|l|}{ Gender } \\
\hline Male & 883 & 56.6 & 1,526 & 51.3 & 0.001 \\
\hline \multicolumn{6}{|l|}{ US census region } \\
\hline Northeast & 145 & 9.3 & 288 & 9.7 & 0.672 \\
\hline Midwest & 450 & 28.8 & 911 & 30.6 & 0.213 \\
\hline South & 769 & 49.3 & 1,350 & 45.4 & 0.012 \\
\hline West & 197 & 12.6 & 427 & 14.3 & 0.108 \\
\hline \multicolumn{6}{|c|}{ Household income (USD) } \\
\hline$<\$ 30,000$ & 336 & 21.5 & 560 & 18.8 & 0.030 \\
\hline$\$ 30,000-\$ 49,999$ & 306 & 19.6 & 543 & 18.3 & 0.266 \\
\hline$\$ 50,000-\$ 69,999$ & 332 & 21.3 & 645 & 21.7 & 0.753 \\
\hline$\$ 70,000-\$ 99,999$ & 238 & 15.3 & 509 & I7.I & 0.109 \\
\hline$\geq \$ 100,000$ & 247 & 15.8 & 528 & 17.7 & 0.103 \\
\hline Missing & 102 & 6.5 & 191 & 6.4 & 0.880 \\
\hline \multicolumn{6}{|l|}{ Race } \\
\hline White $^{a}$ & 1340 & 85.8 & 2484 & 83.5 & 0.037 \\
\hline Non-white & 199 & 12.8 & 450 & 15.1 & 0.030 \\
\hline Missing & 22 & 1.4 & 42 & 1.4 & 0.996 \\
\hline
\end{tabular}

Notes: aNon-Hispanic Caucasian; ${ }^{b}$ Non-white includes Hispanic; African American, Asian, other race/ethnicity.

one SABA fill compared with $32.5 \%$ of the fluticasone/ salmeterol cohort $(P=0.003)$, and $17.1 \%$ of the tiotropium cohort used oxygen services compared with $12.7 \%$ of the fluticasone/salmeterol cohort $(P<0.001)$. In addition, a significantly higher proportion of the tiotropium cohort had a CCI score of $1(50.8 \%$ versus $47.0 \%$ in the fluticasone/ salmeterol cohort, $P=0.013)$ or a CCI score of $4(5.0 \%$ versus $3.5 \%$ of fluticasone/salmeterol patients, $P=0.014$ ); conversely, a significantly lower proportion of tiotropium patients $(11.5 \%)$ had a CCI score of 0 compared with the fluticasone/salmeterol cohort $(19.2 \%, P<0.001)$.

Tiotropium patients had higher mean unadjusted adherence during follow up, on average, than did fluticasone/ salmeterol patients. The mean (SD) unadjusted MPRs for the tiotropium and fluticasone/salmeterol cohorts were $0.38(0.34)$ and $0.26(0.28)$, respectively $(P<0.001$, data not shown). (MPR may also be adjusted for time spent in inpatient facilities by subtracting the number of inpatient days only from the denominator. ${ }^{28}$ We tested the sensitivity of our MPR measure by calculating adherence as (cumulative days supply of index therapy during follow-up)/(length of
Table 2 Baseline clinical characteristics by index therapy cohort

\begin{tabular}{|c|c|c|c|c|c|}
\hline & \multicolumn{2}{|c|}{$\begin{array}{l}\text { Tiotropium } \\
(N=I 56 I)\end{array}$} & \multicolumn{2}{|c|}{$\begin{array}{l}\text { Fluticasone/ } \\
\text { salmeterol } \\
(\mathbf{N}=\mathbf{2 9 7 6})\end{array}$} & \multirow[t]{2}{*}{$P$-value } \\
\hline & $\mathbf{N}$ & $\%$ & $\mathbf{N}$ & $\%$ & \\
\hline \multicolumn{6}{|c|}{ Respiratory complication } \\
\hline $\begin{array}{l}\text { Present during } \\
\text { baseline }\end{array}$ & 202 & 12.9 & 380 & 12.8 & 0.870 \\
\hline \multicolumn{6}{|l|}{ Comorbid conditions } \\
\hline Hypertension & 688 & 44.1 & 1277 & 42.9 & 0.452 \\
\hline Heart disease & 703 & 45.0 & 1223 & $4 I .1$ & 0.011 \\
\hline $\begin{array}{l}\text { Disorders of lipid } \\
\text { metabolism }\end{array}$ & 613 & 39.3 & 1114 & 37.4 & 0.226 \\
\hline $\begin{array}{l}\text { Respiratory } \\
\text { infections }\end{array}$ & 588 & 37.7 & 1238 & 41.6 & 0.010 \\
\hline \multicolumn{6}{|l|}{ Use of breathing agents } \\
\hline $\begin{array}{l}\text { Use of short-acting } \\
\text { beta-agonist }\end{array}$ & 576 & 36.9 & 967 & 32.5 & 0.003 \\
\hline Use of corticosteroid & 303 & 19.4 & 509 & I7.1 & 0.054 \\
\hline Use of oxygen & 267 & 17.1 & 377 & 12.7 & $<0.001$ \\
\hline \multicolumn{6}{|c|}{ Charlson Comorbidity Index score } \\
\hline 0 & 179 & 11.5 & 572 & 19.2 & $<0.001$ \\
\hline I & 793 & 50.8 & 1397 & 47.0 & 0.013 \\
\hline 2 & 298 & 19.1 & 510 & 17.1 & 0.102 \\
\hline 3 & 148 & 9.5 & 275 & 9.2 & 0.791 \\
\hline 4 & 78 & 5.0 & 104 & 3.5 & 0.014 \\
\hline$\geq 5$ & 65 & 4.1 & 118 & 4.0 & 0.746 \\
\hline
\end{tabular}

follow-up - inpatient days). MPR was not sensitive to this variation in measurement. The mean (SD) MPR over the entire study population when number of inpatient days was subtracted from both the numerator and denominator was $0.30(0.31)$. The revised mean (SD) MPR was 0.31 (0.31)).

The proportions of patients with discontinuations measured with 30 day and 60 day gaps are displayed in Figure 2. The great majority of all patients had at least one gap in index therapy during their follow up periods; $84.8 \%$ of tiotropium patients had at least one minimum 30-day gap compared with $94.1 \%$ of fluticasone/salmeterol patients $(P<0.001)$, and $77.6 \%$ and $88.9 \%$ of tiotropium and fluticasone/salmeterol patients, respectively, had minimum 60 day gaps $(P<0.001)$. The low overall continuous adherence and high rate of discontinuation account for the low proportions of adherent patients, also shown in Figure 2. Less than $20 \%$ of each cohort was adherent, although the tiotropium cohort exhibited a higher adherence rate $(19.5 \%)$ than did the fluticasone/salmeterol cohort (8.5\%, $P<0.001)$.

Mean follow up respiratory-related costs are shown in Tables 3 and 4. Table 3 provides a comparison of unadjusted mean costs between the study cohorts. The tiotropium cohort had significantly higher unadjusted mean 


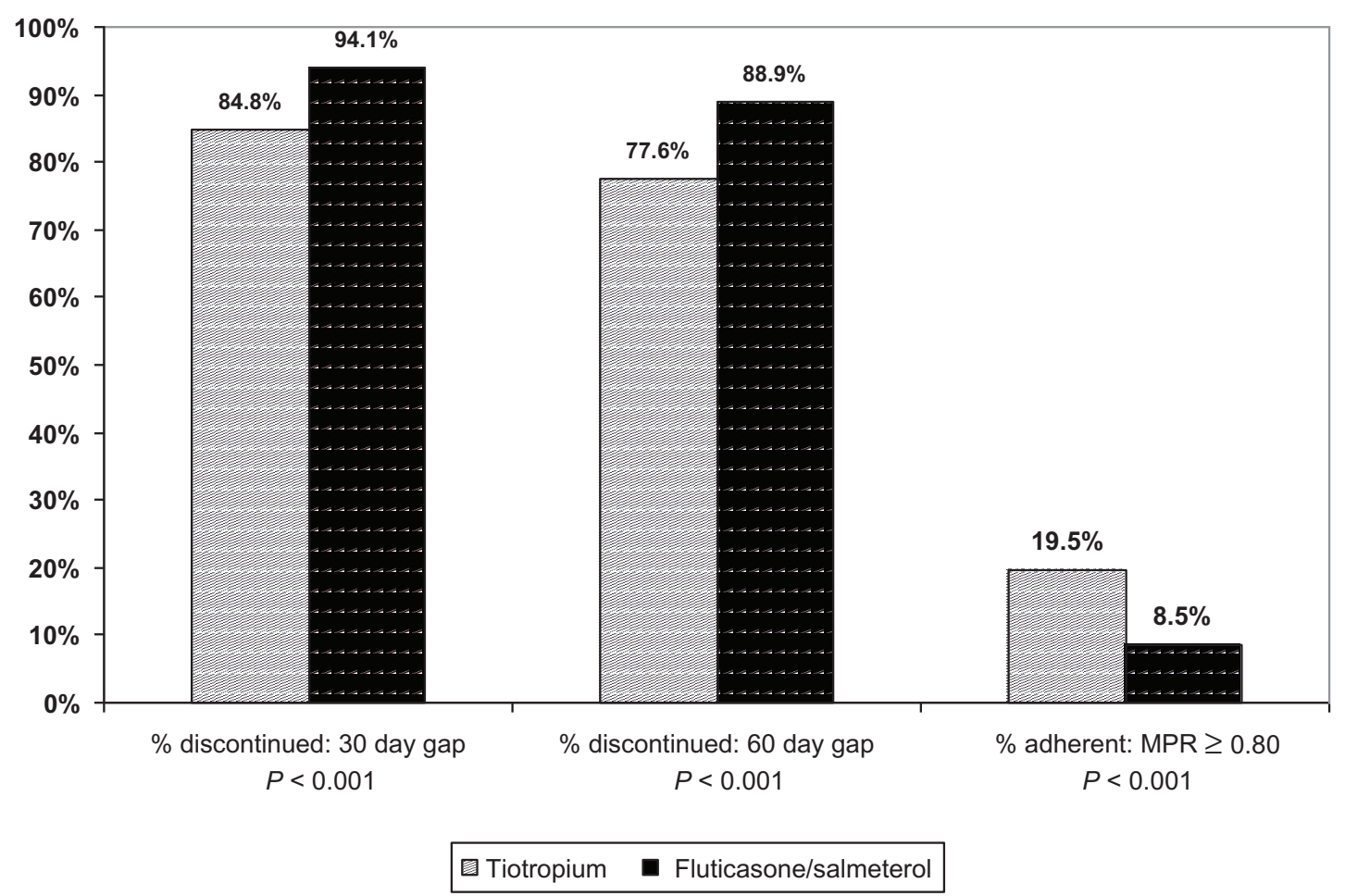

Figure 2 Unadjusted discontinuation and adherence by index therapy cohort.

[SD] respiratory-related pharmacy costs (US\$1080 [1096]) compared with the fluticasone/salmeterol cohort (US\$974 [1124], $P=0.002)$. The tiotropium cohort also had higher mean unadjusted respiratory-related health care costs (US\$3751 $[13,462]$ ) relative to the fluticasone/salmeterol cohort (US\$2932 [9137], $P=0.031$ ). Table 4 provides withincohort comparisons of unadjusted mean respiratory-related cost outcomes stratified by adherence. Unadjusted mean pharmacy costs were higher among adherent patients in both cohorts (US\$2405 [1048] among adherent tiotropium patients versus US\$759 [835] among nonadherent tiotropium patients, $P<0.001 ;$ US\$3148 [1153] and US\$772 [882] among adherent and nonadherent fluticasone/salmeterol patients, respectively, $P<0.001)$. There were no other significant differences within the tiotropium cohort. Within the fluticasone/ salmeterol cohort, nonadherent patients had significantly higher unadjusted mean respiratory-related inpatient costs (US\$1307 [8714]) compared with adherent patients (US\$604 [2441], $P=0.002)$, while adherent patients had higher unadjusted total health care costs (US\$4650 [3752]) versus nonadherent patients (US\$2772 [9468], $P=0.002$ ).

\section{Multivariate analysis results}

The hazard ratios associated with the index therapy cohort indicator (reference $=$ tiotropium cohort) from both Cox proportional hazards regressions are displayed in Figure 3. The hazard ratios for the cohort indicator were $0.68(95 \%$ confidence interval [CI]: $0.64-0.73, P<0.01)$ for the 30 day gap criterion and 0.72 (CI: $0.67-0.77, P<0.01$ ) for the 60 day gap criterion. Thus, the fluticasone/salmeterol cohort was about $39 \%-47 \%$ more likely to discontinue with either gap threshold compared with the tiotropium cohort. Post-estimation tests of the proportional hazards assumption based on Schoenfeld residuals showed that the likelihood

Table 3 Unadjusted respiratory-related costs by index therapy cohort

\begin{tabular}{|c|c|c|c|c|c|}
\hline & \multicolumn{2}{|c|}{$\begin{array}{l}\text { Tiotropium } \\
(\mathbf{N}=\text { I56I) }\end{array}$} & \multicolumn{2}{|c|}{$\begin{array}{l}\text { Fluticasonel } \\
\text { salmeterol } \\
(\mathbf{N}=\mathbf{2 9 7 6}) \\
\end{array}$} & \multirow[t]{2}{*}{$P$-value } \\
\hline & Mean & SD & Mean & SD & \\
\hline $\begin{array}{l}\text { Inpatient stay } \\
\text { costs }\end{array}$ & 1646 & $\mathrm{II}, 074$ & 1248 & 8368 & 0.213 \\
\hline Medical costs & 2671 & 13,334 & 1958 & 8956 & 0.058 \\
\hline $\begin{array}{l}\text { Outpatient } \\
\text { pharmacy costs }\end{array}$ & 1080 & 1096 & 974 & 1124 & 0.002 \\
\hline $\begin{array}{l}\text { Health care } \\
\text { costs }\end{array}$ & 3751 & 13,462 & 2932 & 9137 & 0.031 \\
\hline
\end{tabular}

Note: All costs were measured in 2006 US dollars and during follow-up period. Inpatient stay costs are costs associated with inpatient facility stays; medical costs are costs for all medical services, including inpatient costs; health care costs are the sum of medical and outpatient pharmacy costs.

Abbreviation: SD, standard deviation. 
Table 4 Unadjusted respiratory-related costs by adherence level

\begin{tabular}{|c|c|c|c|c|c|c|c|c|c|c|}
\hline & \multicolumn{4}{|c|}{ Tiotropium } & \multirow[t]{3}{*}{$P$-value } & \multicolumn{4}{|c|}{ Fluticasone/salmeterol } & \multirow[t]{3}{*}{$P$-value } \\
\hline & \multicolumn{2}{|c|}{$\begin{array}{l}\text { Adherent }^{\mathrm{a}} \\
(\mathrm{N}=\mathbf{3 0 5})\end{array}$} & \multicolumn{2}{|c|}{$\begin{array}{l}\text { Nonadherent } \\
(N=1256)\end{array}$} & & \multicolumn{2}{|c|}{$\begin{array}{l}\text { Adherent } \\
(\mathrm{N}=253)\end{array}$} & \multicolumn{2}{|c|}{$\begin{array}{l}\text { Nonadherent } \\
(N=2723)\end{array}$} & \\
\hline & Mean & SD & Mean & SD & & Mean & SD & Mean & SD & \\
\hline Inpatient stay costs & 1412 & 14,523 & 1703 & 10,066 & $0.74 I$ & 604 & 2441 & 1307 & 8714 & 0.002 \\
\hline Medical costs & 2539 & 14,897 & 2703 & 12,932 & 0.860 & 1502 & 3328 & 2001 & 9307 & 0.070 \\
\hline Outpatient pharmacy costs & 2405 & 1048 & 759 & 835 & $<0.001$ & 3148 & 1153 & 772 & 882 & $<0.00$ I \\
\hline Health care costs & 4945 & 15,076 & 3462 & 13,030 & 0.115 & 4650 & 3752 & 2772 & 9468 & 0.002 \\
\hline
\end{tabular}

Notes: All costs were measured in 2006 US dollars and during follow-up period. Inpatient stay costs are costs associated with inpatient facility stays; medical costs are costs for all medical services, including inpatient costs; health care costs are the sum of medical and outpatient pharmacy costs. ${ }^{a} \mathrm{Adherent}=$ continuous medication possession ratio $\geq 0.80$

Abbreviation: SD, standard deviation.

of discontinuation was proportional for the cohort indicator throughout the follow up period.

Figure 4 provides odds ratios (ORs) for the cohort indicator (reference $=$ tiotropium) from logistic regressions used to model adherence at the MPR $\geq 0.80$ and MPR $\geq 0.70$ thresholds. The results for both adherence thresholds showed that the tiotropium cohort had significantly higher odds of adherence relative to the fluticasone/salmeterol cohort. The OR for the cohort indicator at the MPR $\geq 0.80$ adherence threshold was 2.25 (CI: $1.85-2.73, P<0.01$ ); the OR at the
MPR $\geq 0.70$ threshold was 2.03 (CI: $1.70-2.41, P<0.01$ ). Post-estimation Hosmer-Lemeshow tests showed good model fit, as did receiver operating characteristic (ROC) analysis (ROC between 0.72 and 0.73 ).

The coefficients for the cohort and adherence indicators from the cost regressions are shown in Table 5. The cohort indicator was not significant in any of the cost regressions. The adherence indicator (reference $=$ MPR $\geq 0.80$ ) was significant in four of the five regressions. Adherence was associated with $46.9 \%$ higher respiratory-related health care

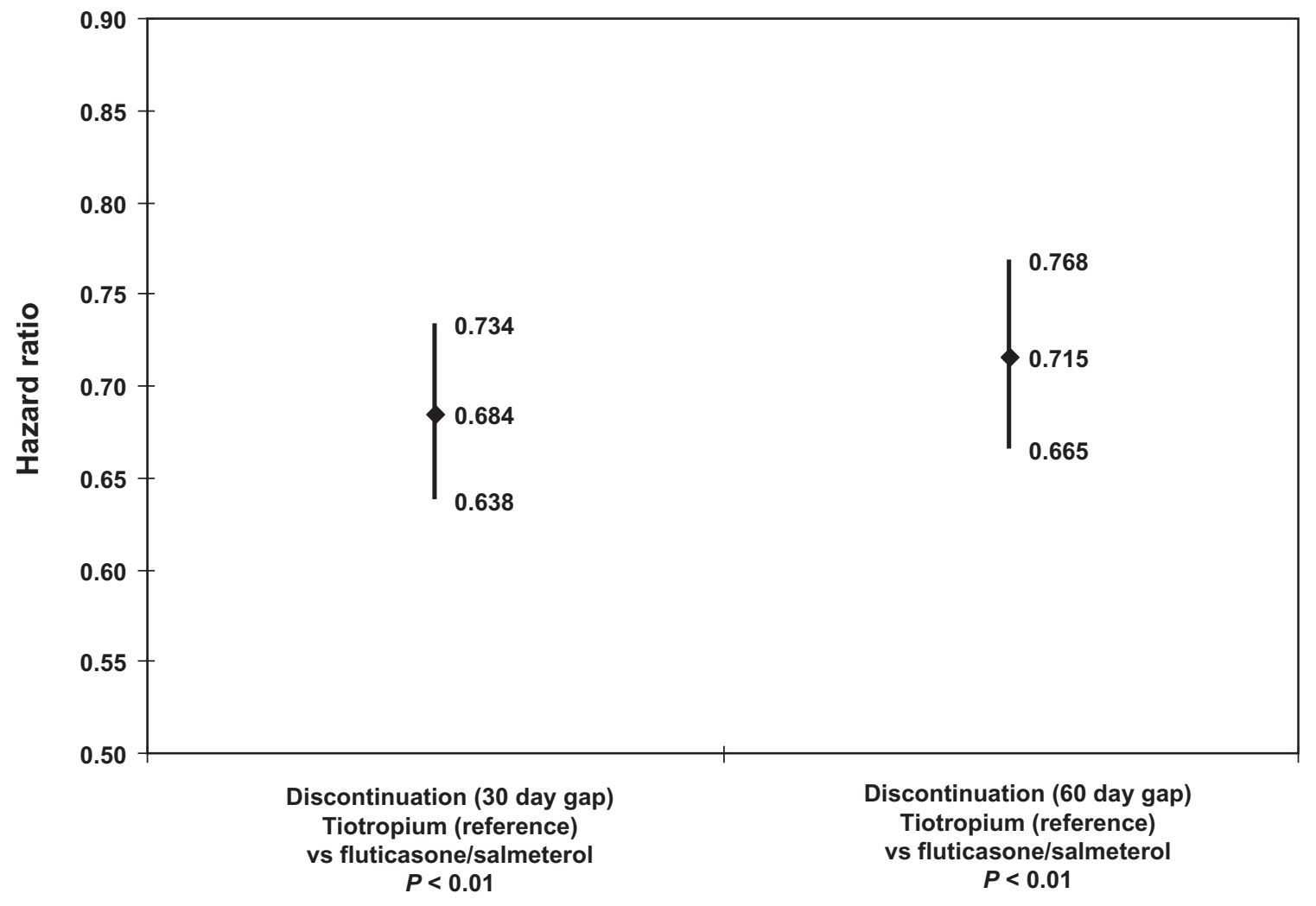

Figure 3 Regression-adjusted discontinuation: index therapy cohort.

Notes: Controlled for: age category; gender; baseline respiratory complication; baseline Charlson Comorbidity Index score; household income; race; pulmonologistprescribed index therapy fill; baseline use of corticosteroid, short-acting beta- agonist, oxygen; baseline hypertension, heart disease, respiratory infection, lipid metabolism disorder. 


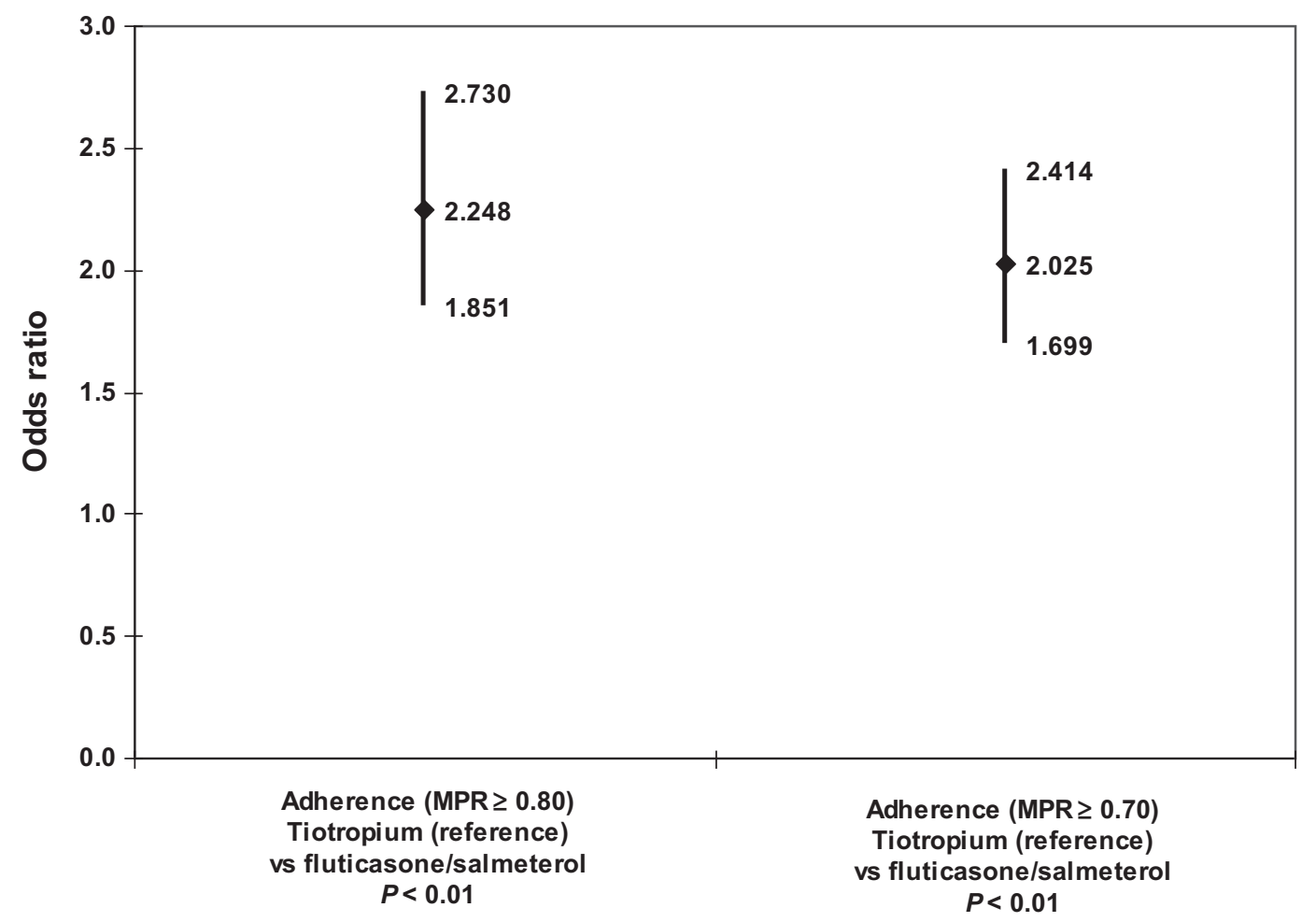

Figure 4 Regression-adjusted adherence: index therapy cohort.

Notes: Controlled for: age category; gender; baseline respiratory complication; baseline Charlson Comorbidity Index score; household income; race; pulmonologist-prescribed index therapy fill; baseline use of corticosteroid, short-acting beta- agonist, oxygen; baseline hypertension, heart disease, respiratory infection, lipid metabolism disorder.

Abbreviation: MPR, medication possession ratio.

(medical + outpatient pharmacy) costs compared with nonadherence (CI: 1.13-1.91, $P<0.01)$. Adherence was associated with $42.2 \%$ higher odds of incurring any respiratory-related medical cost $>\$ 0(\mathrm{CI}: 1.07-1.90 P<0.05)$ and was associated with lower respiratory-related medical costs among patients with any medical costs (cost ratio: 0.63, CI: $0.43-$ 0.91, $P<0.05$ ). Additionally, adherence was associated with significantly lower respiratory-related inpatient costs among patients with inpatient cost $>\$ 0$ (cost ratio: 0.47 , CI: $0.30-0.72, P<0.01)$. There was no effect on cost regression results with respect to the index therapy cohort as a result of the sensitivity testing (adding geographic region indicators, excluding adherence indicator; results not shown).

\section{Discussion}

We examined medical claims data for patients with COPD who initiated tiotropium or fluticasone/salmeterol therapy and observed their index therapy treatment outcomes and respiratory-related cost outcomes for 12-18 months after initiation. Regression analysis showed a strong association between index therapy cohort and the odds of adherence, as well as between cohort and gaps in therapy. The adherence

Table 5 Regression-adjusted respiratory-related costs: index therapy cohort and adherence

\begin{tabular}{|c|c|c|c|c|c|}
\hline & \multirow{2}{*}{$\begin{array}{l}\text { Health care } \\
\text { costs } \\
\text { Cost ratio } \\
(95 \% \mathrm{Cl})\end{array}$} & \multicolumn{2}{|l|}{ Medical costs } & \multicolumn{2}{|c|}{ Inpatient costs } \\
\hline & & $\begin{array}{l}\text { Odds ratio } \\
(95 \% \mathrm{Cl})\end{array}$ & $\begin{array}{l}\text { Cost ratio } \\
(95 \% \mathrm{Cl})\end{array}$ & $\begin{array}{l}\text { Odds ratio } \\
(95 \% \mathrm{Cl})\end{array}$ & $\begin{array}{l}\text { Cost ratio } \\
(95 \% \mathrm{Cl})\end{array}$ \\
\hline Cohort (tiotropium = I) & $\begin{array}{l}0.999 \\
(0.83|-| .202)\end{array}$ & $\begin{array}{l}0.925 \\
(0.777-1.102)\end{array}$ & $\begin{array}{l}1.061 \\
(0.809-1.392)\end{array}$ & $\begin{array}{l}0.905 \\
(0.724-|.| 3 \mid)\end{array}$ & $\begin{array}{l}1.175 \\
(0.849-1.627)\end{array}$ \\
\hline $\begin{array}{l}\text { Adherent to index therapy } \\
(M P R \geq 0.80)\end{array}$ & $\begin{array}{l}1.469 \\
(1.131-1.908)^{a}\end{array}$ & $\begin{array}{l}1.422 \\
(1.067-1.896)^{\mathrm{b}}\end{array}$ & $\begin{array}{l}0.629 \\
(0.434-0.912)^{b}\end{array}$ & $\begin{array}{l}0.883 \\
(0.648-1.202)\end{array}$ & $\begin{array}{l}0.466 \\
(0.303-0.719)^{a}\end{array}$ \\
\hline Observations & 4244 & 4244 & 3478 & 4244 & 441 \\
\hline
\end{tabular}

Notes: a $P<0.01$; ${ }^{b} 0.01 \leq P<0.05$. Controlled for: age category; gender; baseline respiratory complication; baseline Charlson comorbidity index score; household income; race; pulmonologist-prescribed index therapy fill; baseline line of corticosteroid, short-acting beta-agonist, oxygen; baseline hypertension, heart disease, respiratory infection, lipid metabolism disorder. All costs were measured in 2006 US dollars and during follow-up period.

Abbreviations: $\mathrm{Cl}$, confidence interval; MPR, medication possession ratio. 
regression confirmed our hypothesis of a difference in adherence between the index therapy cohorts. This difference may be attributable in part to the relatively more convenient dosing schedule for tiotropium (one inhalation per day) compared with that for fluticasone/salmeterol (two inhalations per day). ${ }^{36,37}$ Tiotropium patients had higher odds of adherence (MPR $\geq 0.80$ ), and were significantly less likely to have gaps in their therapy compared with the fluticasone/ salmeterol cohort after controlling for demographic and baseline clinical characteristics.

The tiotropium cohort had higher mean unadjusted respiratory-related outpatient pharmacy and total respiratoryrelated health care costs compared with the fluticasone/salmeterol cohort. The higher mean respiratory-related pharmacy cost could have been a function of higher adherence in the tiotropium cohort, and the higher mean respiratory-related total health care costs, in turn, could have been, in part, a function of the higher mean pharmacy costs and sicker patients based on demographic and clinical characteristics that we were able to measure (Tables 1 and 2). There was, however, no regression-adjusted association between index therapy cohort and any of the cost outcomes; thus, the significant differences in mean respiratory-related total health care costs between the index therapy cohorts, shown in Table 2, did not persist when factors associated with costs were controlled for in the multivariate analysis. Despite higher adherence levels, respiratory-related costs for the tiotropium cohort were not significantly different from those in the fluticasone/ salmeterol cohort.

In the first part of the two-part respiratory-related medical cost model, adherence was associated with higher odds of having a medical cost (ie, cost >US\$0). This result indicates that patients who are more adherent to tiotropium or fluticasone/salmeterol have higher odds of medical services consumption. One explanation for this result is that adherent patients have more frequent contact with the medical system than do nonadherent patients because adherent patients obtain more prescriptions for their therapies. Moreover, it is possible that, in general, patients who are adherent are also more active in seeking medical care in addition to prescriptions. In the second part of the two-part model, adherence was associated with lower respiratory-related medical costs among patients who incurred any respiratory-related medical costs, as hypothesized. Thus, the two-part model suggests that: 1) among all patients, adherent patients had higher odds of receiving medical treatment for respiratory-related conditions; and 2) among the subset of patients who had a respiratory-related medical cost, those costs were lower among adherent patients.

Adherence was associated with higher respiratory-related health care costs, most likely as a function of higher odds of incurring respiratory-related medical costs (shown in part 1 of the respiratory-related medical cost model) as well as higher respiratory-related pharmacy costs among adherent patients (as shown in Table 4). Even though the association between adherence and respiratory-related pharmacy costs was not evaluated with regression analysis, the difference in unadjusted mean respiratory-related costs is large enough that one can reasonably surmise that they are an important cost driver.

Finally, adherence was associated with lower respiratory-related inpatient costs among patients with any respiratory-related inpatient costs. Respiratory-related inpatient costs were a subset of respiratory-related medical costs. Mean respiratory-related inpatient costs accounted for $61.6 \%$ and $63.7 \%$ of mean respiratory-related medical costs in the tiotropium and fluticasone/salmeterol cohorts, respectively (Table 3 ). This suggests that the association between adherence to long-acting bronchodilators and respiratoryrelated medical costs was partially driven by the association between adherence and respiratory-related inpatient costs. Adherence was not associated with the odds of having a respiratory-related inpatient cost. The lack of a significant effect for adherence may be attributable to insufficient sample size or unobserved factors that also may affect the odds of a respiratory-related inpatient stay.

The result that better adherence to therapy is associated with lower respiratory-related medical and inpatient costs is consistent with the relationships between adherence and cost outcomes in the literature. Also consistent with the literature were the tiotropium and fluticasone/salmeterol adherence estimates within our study population; the mean MPRs in our study population -0.38 in the tiotropium cohort and 0.26 in the fluticasone/salmeterol cohort - align with adherence estimates of $10 \%-40 \%$ in clinical practice documented by Bourbeau and Bartlett. ${ }^{14}$ Low adherence to inhaled medications is not unique to COPD; it has also been documented among individuals using inhaled therapies for treatment of asthma. ${ }^{15,38}$

Barriers to improved adherence to inhaled bronchodilator therapy are well documented and include complexity of regimen, frequency of dosing, and polypharmacy, as well as patient characteristics such as change in lifestyle, behavior, trust and belief in provider and treatment efficacy, concern about side effects, forgetfulness, or misunderstanding of 
dosing instruction..$^{13,14,16,21,39}$ The capacity to achieve better adherence to inhaled therapies by addressing some of the barriers to good adherence should result in better outcomes for COPD patients. Interventions to improve adherence can include: patient education, both to bolster understanding of COPD and the impact of inhaled therapies in retarding disease progress and to ensure that patients receive reinforced instruction in appropriate medication administration; strategies, developed with patients, to make adherence easier (eg, timing inhaler administration to coincide with other daily activities); and structured interactions with patients emphasizing active self-management. ${ }^{13,14}$

It is also worth noting, however, that improved adherence may not result in reduced overall health care expenditures. We found adherence, relative to nonadherence, was associated with higher respiratory-related health care costs. Similarly, Delea et al found that increased adherence to fluticasone/salmeterol was associated with higher asthma-related costs. ${ }^{12}$ These results should be interpreted carefully insofar as they are condition-specific costs, and not overall health care expenditures. Future research should evaluate the impact of improved adherence to long-term COPD therapies on total health care expenditures as well as on indirect costs, such as gains in productivity from delayed or prevented disability.

The results of this study should be interpreted in light of several limitations. There are inherent limitations in administrative claims data. We cannot observe whether medications were used as prescribed; this may affect the accuracy of therapy outcomes. The presence of a diagnosis code on a medical claim does not necessarily confirm a clinical condition such as COPD, as the diagnosis code may be incorrect or the result of rule-out. Costs were defined as costs incurred by the health plan and the patient; costs covered by a third-party payer were not available from the data. Lack of third-party coverage data is principally a concern for subjects at least 65 years old who may have both traditional Medicare and commercial health plan coverage. Thus, some costs may be underestimated. Claims data do not contain clinical information, such as forced expiratory volume or spirometry test results, that would allow us to measure COPD severity or other characteristics associated with costs. There was some claims data-based evidence pointing to a potential difference in health status and COPD severity between the tiotropium and fluticasone/salmeterol cohorts (ie, higher CCI score and higher proportions of patients with baseline SABA and oxygen use in the tiotropium cohort), but it is difficult to assess clinically important differences in the absence of clinical measures not found in administrative claims. Moreover, the relationship between adherence and clinical outcomes could not be measured with these data. We did, however, control for the available measures of health status and COPD severity in the regression analyses.

There were also some limitations in the study design and measurement. The study design excluded patients with baseline use of any long-acting bronchodilator therapy. Consequently, the study population could have excluded patients who had failed on prior bronchodilator treatment. We examined the data and found that 46 patients who initiated tiotropium and 43 patients who initiated fluticasone/salmeterol had at least one fill of a nonindex long-acting bronchodilator during the baseline period. When those 46 and 43 patients were added to the tiotropium and fluticasone/salmeterol cohorts, respectively, the distribution of age category, gender, and rates of baseline respiratory complications, SABA use, and oxygen use (data not shown) across cohorts stayed virtually the same as those shown in Tables 1 and 2. The only difference for which the significance level changed was that between the proportions of tiotropium patients (19.9\%) and fluticasone/ salmeterol patients $(17.3 \%)$ with baseline corticosteroid use $(P=0.026)$. Therefore, the exclusion of patients with any baseline long-acting bronchodilator use was unlikely to have changed the analysis results. It is possible that regression results were affected by some degree of selection bias with respect to assignment of patients into the tiotropium and fluticasone/salmeterol cohorts. It is likely that coefficients were affected by omitted, unmeasured (and unavailable) variables associated with providers' decisions to initiate patients on tiotropium or fluticasone/salmeterol, eg, physicians' assessments of potential side effects, experience with tiotropium or fluticasone/salmeterol in other patients, or simple preference. Cost outcomes were measured over variable lengths of follow up, ranging from 12 to 18 months. The lengths of follow up were very close between the cohorts, as described previously, so it is unlikely that this influenced the comparisons; and, respiratory-related costs pertained to a variety of respiratory disorders. Therefore, it is likely that only a proportion of the costs reported are attributable to the treatment of COPD. Nevertheless, COPD patients are likely to have concomitant respiratory disorders, and these costs should provide a good estimate of overall expenditures associated with respiratory-related care.

Finally, the results of this analysis cannot be generalized to individuals with COPD who began treatment on tiotropium or fluticasone/salmeterol after previous long-acting bronchodilator therapy or to those treated with salmeterol 
or formoterol. Moreover, these results are not generalizable to patients with COPD and comorbid asthma.

\section{Conclusion}

Overall, less than $20 \%$ of patients with COPD who initiated long-acting bronchodilator therapy were adherent to their therapies. Patients initiating tiotropium therapy, however, were more than twice as likely to be adherent than were those initiating fluticasone/salmeterol. The majority of all patients (at least $84 \%$ ) experienced a minimum 30 day gap in therapy, although patients initiating on fluticasone/salmeterol were significantly more likely to discontinue therapy than were those initiating tiotropium. Adherence to either tiotropium or fluticasone/salmeterol was associated with lower respiratory-related medical costs and inpatient costs, while there were no associations between index therapy cohort and respiratory-related cost outcomes. Adherence is an important treatment objective that is crucial for preventing COPD-related exacerbations and preserving respiratory function. Nevertheless, it is important to recognize that improved adherence may be associated with higher overall expenditures. Further research should model the impact of improved adherence to COPD long-acting bronchodilator therapy on overall direct and indirect costs.

\section{Acknowledgment}

The authors thank Kiran Gupta, $\mathrm{PhD}$, for her contributions to earlier drafts of this manuscript.

\section{Disclosure}

This study was funded through a research contract with Boehringer Ingelheim Pharmaceuticals, Inc and Pfizer, Inc. OptumInsight received financial support from Boehringer Ingelheim, Inc and Pfizer, Inc as part of this research contract. RH and VP are employees of OptumInsight. CLB, KBW, and RPR are employees of Pfizer, Inc, and own Pfizer, Inc, stock. JS is an employee of Boehringer Ingelheim Pharmaceuticals, Inc, and HS was an employee of Boehringer Ingelheim Pharmaceuticals, Inc at the time this study was conducted.

Portions of this analysis were presented in posters at the International Society for Pharmacoeconomics and Outcomes Research 14th Annual International Meeting on May 19, 2009, Orlando, FL.

\section{References}

1. Williams DM, Bourdet SV. Chronic obstructive pulmonary disease. In: DiPiro JT, Talbert R, Yee G, et al, editors. Pharmacotherapy: A Pathophysiologic Approach. 7th ed. New York, NY: McGraw Hill Medical;2008:495-517.
2. Global Initiative for Chronic Obstructive Lung Disease. Global strategy for the diagnosis, management, and prevention of COPD. Updated December 2009. Available from: http://www.goldcopd.org/ Guidelineitem.asp?11=2\&12=1\&intId=2003. Accessed May 6, 2011.

3. National Heart, Lung and Blood Institute. Chronic obstructive pulmonary disease: data Fact Sheet. Bethesda: US Department of Health and Human Services. National Institutes of Health. NIH Publication No. 03-5529; 2003.

4. Mannino DM, Homa DM, Akinbami LJ, Ford ES, Redd SC. Chronic obstructive pulmonary disease surveillance - United States, 1971-2000. MMWR Surveill Summ. 2002;51(6):1-16.

5. National Heart, Lung and Blood Institute. COPD Fact Sheet. Bethesda: US Department of Health and Human Services. National Institutes of Health. NIH Publication No. 03-5229; March 2003.

6. National Heart, Lung and Blood Institute. Morbidity and Mortality: 2007 Chart Book on Cardiovascular, Lung and Blood Disorders. National Institutes of Health; June 2007.

7. Hanania NA. The impact of inhaled corticosteroid and long-acting betaagonist combination therapy on outcomes in COPD. Pulm Pharmacol Ther. 2008;21(3):540-550.

8. Gross N, Levin D. Primary care of the patient with chronic obstructive pulmonary disease part 2: pharmacologic treatment across all stages of disease. Am J Med. 2008;121 Supp1 7:S13-S24.

9. Foster JA, Yawn BP, Maziar A, Jenkins T, Rennard SI, Casebeer L. Enhancing COPD management in primary care settings. MedGenMed. 2007;9(3):24.

10. Diette GB, Orr P, McCormack MC, Gandy W, Hamar B. Is pharmacologic care of chronic obstructive pulmonary disease consistent with the guidelines? Popul Health Manag. 2010;13(1):21-26.

11. Ramsey SD. Suboptimal medical therapy in COPD: exploring the causes and consequences. Chest. 2000;117(Suppl 2):33S-37S.

12. Delea TE, Stanford RH, Hagiwara M, Stempel DA. Association between adherence with fixed dose combination fluticasone propionate/ salmeterol on asthma outcomes and costs. Curr Med Res Opin. 2008;24(12): 3435-3442.

13. Rand CS. Patient adherence with COPD therapy. Eur Respir Rev. 2005; 14:97-101.

14. Bourbeau J, Bartlett SJ. Patient adherence in COPD. Thorax. 2008;63(9):831-838.

15. Krigsman K, Nilsson LG, Ring L. Refill adherence for patients with asthma and COPD: comparison of a pharmacy record database with manually collected repeat prescriptions. Pharmacoepidemiol Drug Saf. 2007;16(4):441-448.

16. George J, Kong DCM, Thoman R, Stewart K. Factors associated with medication non-adherence in patients with COPD. Chest. 2005;128(5): 3198-3204.

17. Jung E, Pickard AS, Salmon JW, Bartle B, Lee TA. Medication adherence and persistence in the last year of life in COPD patients. Respir Med. 2009;103(4):525-534.

18. Delea TE, Hagiwara M, Dalal AA, Stanford RH, Blanchette CM. Healthcare use and costs in patients with chronic bronchitis initiating maintenance therapy with fluticasone/salmeterol vs other inhaled maintenance therapies. Curr Med Res Opin. 2009;25(1):1-13.

19. Dolce JJ, Crisp C, Manzella B, Richards JM, Hardin JM, Bailey WC. Medication adherence patterns in chronic obstructive pulmonary disease. Chest. 1991;99(4):837-841.

20. Rand CS, Nides M, Cowles MK, Wise RA, Connett J. Long-term metered-dose inhaler adherence in a clinical trial. The Lung Health Study Research Group. Am J Respir Crit Care Med. 1995;152(2): 580-588.

21. Rand CS, Wise RA, Nides M, et al. Metered-dose inhaler adherence in a clinical trial. Am Rev Respir Dis. 1992;146(6):1559-1564.

22. Balkrishnan R, Christensen DB. Inhaled corticosteroid use and associated outcomes in elderly patients with moderate to severe chronic pulmonary disease. Clin Ther. 2000;22(4):452-469.

23. DiMatteo MR. Variations in patients' adherence to medical recommendations: a quantitative review of 50 years of research. Med Care. 2004;42(3):200-209. 
24. Fuso L, Incalzi RA, Pistelli R, et al. Predicting mortality of patients hospitalized for acutely exacerbated chronic obstructive pulmonary disease. Am J Med. 1995;98(3):272-277.

25. Garcia-Aymerich J, Barreiro E, Farrero E, Marrades RM, Morera J, Antó JM. Patients hospitalized for COPD have a high prevalence of modifiable risk factors for exacerbation (EFRAM study). Eur Respir J. 2000;16(6):1037-1042.

26. Sin DD, McAlister FA, Man SF, Anthonisen NR. Contemporary management of chronic obstructive pulmonary disease: scientific review. JAMA. 2003;290(17):2301-2312.

27. Schmier JK, Halpern MT, Jones ML. Effects of inhaled corticosteroids on mortality and hospitalisation in elderly asthma and chronic obstructive pulmonary disease patients: appraising the evidence. Drugs Aging. 2005;22(9):717-729.

28. Andrade SE, Kahler KH, Frech F, Chan KA. Methods for evaluation of medication adherence and persistence using automated databases. Pharmacoepidemiol Drug Saf. 2006;15(8):565-574.

29. Sikka R, Xia F, Aubert RE. Estimating medication persistency using administrative claims data. Am J Manag Care. 2005;11(7):449-457.

30. Chrischilles E, Gilden D, Kubisiak J, Rubenstein L, Shah H. Delivery of ipratropium and albuterol combination therapy for chronic obstructive pulmonary disease: effectiveness of a two-in-one inhaler versus separate inhalers. Am J Manag Care. 2002;8(10):902-911.

31. Comorbidity software: version 3.2. Available from: http://www.hcup-us. ahrq.gov/toolssoftware/ccs/ccs.jsp. Accessed March 4, 2011.
32. Quan H, Sundararajan V, Halfon P, et al. Coding algorithms for defining comorbidities in ICD-9-CM and ICD-10 administrative data. Med Care. 2005;43(11):1130-1139.

33. Deyo RA, Cherkin DC, Ciol MA. Adapting a clinical comorbidity index for use with ICD-9-CM administrative databases. J Clin Epidemiol. 1992;45(6):613-619.

34. Charlson ME, Pompei P, Ales KL, MacKenzie CR. A new method of classifying prognostic comorbidity in longitudinal studies: development and validation. J Chronic Dis. 1987;40(5):373-383.

35. Manning WG, Mullahy J. Estimating log models: to transform or not to transform? J Health Econ. 2001;20(4):461-494.

36. GlaxoSmithKline. Highlights of prescribing information for Advair Diskus. Revised June 2010. Available online at: http://us.gsk.com/ products/assets/us_advair.pdf. Accessed March 4, 2011.

37. Boehringer Ingelheim Pharmaceuticals, Inc. Highlights of prescribing information for Spiriva ${ }^{\circledR}$ HandiHaler $^{\circledR}$. Revised June 2010. Available online at: http://bidocs.boehringer-ingelheim.com/BIWebAccess/ViewServlet.ser?docBase $=$ renetnt $\&$ folderPath=/Prescribing+Information/PIs Spiriva/Spiriva.pdf. Accessed March 4, 2011.

38. Janson C, De Marco R, Accordini S, et al. Changes in the use of antiasthmatic medication in an international cohort. Eur Respir J. 2005; 26(6):1047-1055.

39. Cazzola M, Matera MG. Novel long-acting bronchodilators for COPD and asthma. Br J Pharmacol. 2008;155(3):291-299. 
Appendix A. ICD-9-CM Diagnosis Codes for Respiratory Conditions or Respiratory Failure

\begin{tabular}{ll}
\hline Respiratory Condition & ICD-9-CM Code \\
\hline Acute respiratory infection & $466 . x x$ \\
Pneumonia & $480 . x-487.0$ \\
Chronic bronchitis & $490-491 . x x$ \\
Emphysema & $492 . x$ \\
Bronchiectasis & $494 . x$ \\
Pneumonitis and pneumoconiosis & $495 . x, 500-508 . x$ \\
Chronic obstructive pulmonary disease & 496 \\
Empyema, pleurisy, and pneumothorax & $510 . x-512 . x$ \\
Respiratory failure & $518.8 I-518.84$ \\
Abscess of lung and mediastinum & $513 . x$ \\
Pulmonary congestion and hypostasis & 514 \\
Post-inflammatory pulmonary fibrosis & 515 \\
Other alveolar and parietoalveolar pneumonopathy & $516 . x$ \\
Pulmonary collapse & 518.0 \\
Pulmonary eosinophilia & 518.3 \\
Acute edema of lung, unspecified & 518.4 \\
Pulmonary insufficiency following trauma or surgery & 518.5 \\
Allergic bronchopulmonary aspergillosis & 518.6 \\
Transfusion-related acute lung injury & 518.7 \\
Other diseases of the lung, not elsewhere classified & 518.89 \\
Other diseases of the respiratory system & $519 . x x$ \\
\hline
\end{tabular}

Note: Asthma would have been added as a respiratory condition; however, patients with medical claims with diagnosis codes for asthma were excluded from the study population.
Appendix Conditions

\begin{tabular}{ll}
\hline Cardiac Condition & $\begin{array}{l}\text { ICD-9-CM } \\
\text { Code }\end{array}$ \\
\hline Diseases of mitral valve & $394 . x$ \\
Diseases of aortic valve & $395 . x$ \\
Diseases of mitral and aortic valves & $396 . x$ \\
Rheumatic heart failure (congestive) & 398.91 \\
Hypertensive heart disease & $402 . x x$ \\
Hypertensive heart and chronic kidney disease & $404 . x x$ \\
Acute myocardial infarction & $410 . x x$ \\
Acute pulmonary heart disease & $415 . x x$ \\
Chronic pulmonary heart disease & $416 . x$ \\
Other diseases of pulmonary circulation & $417 . x$ \\
Other diseases of endocardium & $424 . x x$ \\
Cardiomyopathy & $425 . x$ \\
Heart failure & $428 . x x$ \\
Takotsubo syndrome & 429.83 \\
\hline
\end{tabular}

Patient Preference and Adherence

\section{Publish your work in this journal}

Patient Preference and Adherence is an international, peer-reviewed, open access journal focusing on the growing importance of patient preference and adherence throughout the therapeutic continuum. Patient satisfaction, acceptability, quality of life, compliance, persistence and their role in developing new therapeutic modalities and compounds to

\section{Dovepress}

optimize clinical outcomes for existing disease states are major areas of interest. This journal has been accepted for indexing on PubMed Central. The manuscript management system is completely online and includes a very quick and fair peer-review system. Visit http://www.dovepress.com/ testimonials.php to read real quotes from published authors. 